\title{
Consideraciones metodológicas cualitativas para la didáctica de la traducción literaria
}

\author{
Belén Santana López (1) y Ana María García Álvarez (2) \\ bsantana@usal.es/agarcia@dfm.ulpgc.es \\ Universidad de Salamanca (1) y Universidad de Las Palmas \\ de G.C. (2) \\ https://dx.doi.org/10.12795/futhark.2014.i9.15
}

Resumen: Aunque la didáctica de la traducción ha experimentado desde dos décadas un cambio considerable en su investigación, basada en una perspectiva inductivo-experimental y con numerosos trabajos al respecto, la didáctica de la traducción literaria adolece actualmente de andamiajes teoricos y metodológicos apropiados que describan su gran complejidad y puedan ayudar al estudiante a traducir literatura de manera profesional. Nuestro objetivo en la presente comunicación es proponer un andamiaje metodológico que enfatiza precisamente la importancia de establecer aquellos contenidos adecuados que puedan describir la complejidad cognitiva implicada en la práctica de la traducción literaria y que puedan ayudar a desarrollar estrategias de traducción apropiadas. El estudio de la introspección es, en este sentido, esencial. Se aportarán algunos ejemplos de cómo abordar cualitativamente las estrategias traductoras y su aplicación didáctica basados en la traducción Wadzek contra la turbina de vapor, de Alfred Döblin (1918).

Palabras clave: didáctica de la traducción literaria; métodos cualitativos; procesos cognitivos; lingüística cognitiva.

Abstract: Despite the fact that translation teaching has undergone a significant change during the last two decades in relation to research from an 
inductive-experimental perspective, and that much academic work has consequently emerged in this way, the teaching of literary translation currently lacks an appropriate theoretical and methodological scaffolding that may describe its great complexity, and which can help students to translate literature in a professional way. our aim in this article is to propose a methodological scaffolding that emphasizes the importance of establishing those types of content that can be used effectively to describe the cognitive complexity implied in the practice of literary translation, and which may consequently help to develop suitable translation strategies. thus, we believe that the study of introspection is essential. some examples will be presented, based on the translation wadzek contra la turbina de vapor by alfred döblin (1918), in order to deal with translation strategies in a qualitative manner and consequent didactic application.

Key words: literary translation teaching; qualitative methods; cognitive processes; cognitive linguistics.

\section{EL RETORNO A LA INTROSPECCIÓN}

La idea de un modelo capaz de dar cuenta de las funciones y atributos mentales del traductor literario presupone de planteamiento que, nos guste o no, no puede ser completamente verificable de manera experimental en la actualidad, porque no disponemos de herramientas informáticas que funcionen como la mente humana. El empirismo que se está llevando a cabo en el estudio de los procesos traslativos está aún en la etapa de establecer hipótesis muy rudimentarias en relación con la comprensión razonada y compleja de la traducción. Se ha rechazado en gran medida la introspección mental y los primeros trabajos orientados en esta dirección (Kussmaul 1995, 2000; Hönig 1997, entre otros) por considerarse bastante subjetiva y, en particular, por su imposibilidad de describir los procesos inconscientes con objetividad. Por ello, actualmente se aplican experimentos con programas informáticos que estudian especialmente los movimientos corpóreos y sensoriales para deducir algunas hipótesis actitudinales de los sujetos investigados cuando traducen. Sin embargo, estos datos también adolecen de la tan ansiada objetividad en la investigación, ya que el hincapié se ha puesto en un excesivo culto al análisis del cuerpo en detrimento de la mente. Si bien la actitud del cuerpo a la hora de 
traducir, incluyendo también otros aspectos psicomotrices, puede arrojar luz sobre algunas actitudes y estrategias de traducción, lo paradojico en la investigación es que hemos dejado de lado el análisis introspectivo de la mente y su funcionamiento, descartando la posibilidad de apoyarnos también en los modelos deductivos de corte cognitivo por considerarse especulativos y artificiales. La dimension hermenéutica que tiene lugar en los procesos de traducción, por ejemplo, cuando se aborda el análisis profundo de un texto original, no suele ser objeto de interés en la investigación actual, tal vez por su extremada complejidad cognitiva; así, parece preferible continuar investigando y aportando datos empíricos más sencillos y más procedimentales. Pero ¿qué está ocurriendo con la calidad en la docencia y, en concreto, en la docencia de la traducción literaria? ¿Qué andamiajes garantizan la consecución óptima de las competencias de un traductor literario en el aula? ¿Qué cariz debe tomar la investigación en torno a las estrategias de traducción que enseñamos en clase?

Desde luego, la complejidad de la traducción no puede abordarse únicamente desde la investigación experimental mediante el uso de los ordenadores, en particular si hablamos de la traducción literaria y su complejidad. También existen otros parámetros, como los metacognitivos, que inciden en la práctica de la traducción, cuyo análisis es posible mediante la verbalización metalingüística bien argumentada sobre la elección de las estrategias de traducción adoptadas por el sujeto investigado, si lo que queremos es ahondar en su caja negra, reflejo todo ello precisamente de su introspección.

Si retomamos en este sentido las razones por las que se han rechazado considerablemente las verbalizaciones de los estudiantes al aplicarse el método de pensar en voz alta, tan en boga en la década de los 90 , observamos que las debilidades se encuentran en la calidad de las argumentaciones. Los estudiantes no saben comentar ni argumentar sus decisiones y estrategias de traducción. No hay una comprensión razonada sobre el porqué de sus actitudes procedimentales a la hora de traducir. Las argumentaciones se basan en la intuición, pero cuando la intuición falla, no aplican el conocimiento de saber por qué. El estudiante no suele realizar una autoobservación detallada y bien argumentada de su propio proceso traslativo para comprobar si las 
estrategias elegidas son las adecuadas. Estos aspectos guardan rela. ción precisamente con la falta de metacognición, que Martín de Buey et al. (2007) definen como procesos autorregulatorios del funcionamiento de otros procesos cognitivos más específicos de importancia capital en el aprendizaje. De hecho, constituyen los sistemas de alerta y consciencia que han de acompanar toda labor intelectual. Su ausencia en los alumnos provoca, sin embargo, grandes pérdidas de tiempo en el estudio con pobres resultados. Asimismo, se trata de procesos cognitivos inferidos cuando el sujeto "se da cuenta" súbitamente de la solución correcta o de la falta de comprensión que le somete, por ejemplo, a releer el texto; o de la sensación de falta de planificación de la tarea que le propone a él mismo la utilización de procedimientos paso a paso; o de la toma de contacto con la realidad cuando los pensamientos distractores nos sitúan fuera de la tarea.

Kautz (2000:44) afirma que la didáctica de la traducción necesita el conocimiento de la investigación translatológica para el desarrollo de métodos y estrategias adecuadas. En este sentido, el papel principal de la teoría para la didáctica consiste en ofrecer una descripción y explicación del funcionamiento de la traducción que pueda ayudar al estudiantado a reflexionar sobre lo que hace cuando traduce y al profesorado a trazar y elaborar los contenidos de su enseñanza. En la actualidad, los docentes de la traducción estamos tendiendo, sin embargo, al extremo opuesto: a trazar los contenidos curriculares y las estrategias desde una visión de la disciplina marcadamente procedimental. Asimismo, el concepto de calidad de la enseñanza se está enfocando principal y mayoritariamente hacia los formalismos exigidos por los proyectos docentes en el marco de un complejo aparato burocrático de coordinación de asignaturas. Este planteamiento curricular, si bien es importante para la organización y coherencia de objetivos docentes en los grados y másteres, no puede marginar la investigación teórica, pues esta es necesaria para garantizar la calidad en la selección de los contenidos metodológicos que se imparten en los estudios de Traducción e Interpretación en las Universidades.

No obstante, Kautz adolece en sus planteamientos de un enfoque interdisciplinar cuando habla de la importancia de la teoría para la didáctica. Es cierto que la calidad de las estrategias y métodos en la 
práctica debe basarse en el conocimiento de la investigacion traductologica, pero en este sentido es necesario seleccionar aquellos contenidos traductológicos que aporten los andamiajes metodologicos apropiados en función del perfil y conocimiento previo de los estudiantes sobre la traducción literaria. Por otro lado, la traductología -y de ella principalmente las corrientes que den cuenta de un planteamiento relativista sobre la traduccion, cuyo enfoque debe ser funcionalcognitivo y descriptivo- tan solo puede aportar una parte del andamiaje metodológico. El traductor literario representa, esboza y extrae continuamente imágenes cuando traduce, $y$, sin embargo, aún no nos hemos dedicado a investigar en profundidad la complejidad de estos procesos imaginísticos. Existen muy pocos trabajos traductologicos en esta dirección y muy básicos en sus planteamientos (Snell-Hornby 1988; Vermeer y Witte 1990; Kussmaul 2000). Otro reto metodológico es la manera de abordar la enseñanza de la traducción de la metáfora y su construcción y funcionamiento en los textos. Los estudiantes ignoran estas cuestiones cuando empiezan a traducir literatura.

La introspección es por tanto necesaria como vía de análisis del proceso para construir una didáctica apropiada de la traducción literaria. De hecho, el estudio de la metacognición no puede separarse de aquella, porque constituye el conocimiento y regulación de nuestras propias cogniciones y de nuestros procesos mentales, como conocimiento autorreflexivo (Burón, 2006:10).

Para empezar a analizar el conocimiento de la propia mente adquirido por autoobservación o «intracognición» (Burón, 1988), podríamos estudiar las creencias epistemológicas de los estudiantes (Ormrod, 2005:391) sobre la literatura y, en concreto, sobre su traducción (Toda, 2012). Sabemos, por ejemplo, que el proceso de traducción de otros tipos de textos por parte del estudiantado tiende a ser lineal, basado principalmente en la aplicación de microestrategias (Hönig, 1997), en las que predomina un excesivo hincapié en otorgar autoridad a la forma lingüística y al significado estructuralista establecido por los diccionarios. Por otro lado, los argumentos para fundamentar sus estrategias de traducción están normalmente guiados por la intuición. Sería muy interesante estudiar a qué se deben estas tendencias mediante cuestionarios de preguntas abiertas y otros métodos de corte 
cualitationdescription que ya se vienen aplicando por la teoría del aprendizaje y de la pedagogía en otras disciplinas. El objetivo principal de estas investigaciones consistiría en reflexionar sobre los tipos de andamiajes declaration que estamos usando en las clases de traducción literaria, particularmente los relacionados con el conocimiento teórico y con las estrategias aplicadas. Al observar los conocimientos previos que posee el estudiantado sobre la traducción literaria, obtendremos indicios de las razones por las que los estudiantes subestiman o interpretan de forma errónea las tareas de aprendizaje. La experiencia docente demuestra en general que los estudiantes que no disponen de un adecuado cúmulo de conocimientos bien organizado y bien asociado respecto a una actividad tienden a aplicar estrategias de aprendizaje mecánico, normalmente mucho menos eficaces. En otros casos puede ocurrir que el estudiante distorsione la nueva información recibida por el docente para que se adapte a su "propio" conocimiento, por lo que terminará por aprender algo completamente diferente de lo que en realidad está viendo, escuchando o leyendo. Con frecuencia, los profesores presentan a sus alumnos determinada información, convencidos de que eso es suficiente para corregir sus creencias erróneas. Lo que suele suceder es que los alumnos mantienen obstinadamente sus nociones preconcebidas y distorsionan la nueva información para que se ajuste a ellas (Ormrod, 2005:267). Algunas ideas erróneas se integran por ejemplo en un todo coherente, con muchas interrelaciones entre distintas ideas $y$, en estos casos, eliminar las ideas erróneas - cuando el profesor las descubre, pues muchas pueden tomar forma de conocimiento implícito - implica cambiar un cuerpo completo y organizado de conocimiento. Cambiar estos "esquemas mentales" es difícil, aunque no imposible, siempre y cuando se construyan andamiajes optimos aplicables a las distintas e infinitas situaciones de traducción. El aprendizaje significativo solo puede tener lugar cuando los alumnos disponen de un conocimiento previo adecuado con el cual puedan relacionar las ideas nuevas. Sabemos hipotéticamente que cuando procesan las materias de una manera mecánica o memorística, ello se debe probablemente a que carecen del conocimiento apropiado para relacionarlo con ese contenido, a que no saben que lo tienen o que el conocimiento que poseen no sirve para la traducción. 
La inteligencia humana comprende un hábito de actuaciones que $\mathrm{no}^{\mathrm{se}}$ reduce a las formas tradicionales de resolución de problemas mediante el razonamiento, la planificación o la reflexión. Incluye actividades cotidianas en las que exhibimos rutinas con un alto grado de control sensoriomotriz o situaciones en las que el aprendiz ha de responder a las novedades imprevistas del ambiente. Esta es la concepción de la cognición situada y constructivista en la teoría del aprendizaje: son las "prácticas" las que son prioritarias.

Sin negar logicamente la importancia de estas cuestiones constructivistas para la didáctica de la traducción literaria, una de las cuestiones que hay que revisar es el concepto de representación en la teoría del aprendizaje, porque constituye un factor esencial para la construcción de andamiajes óptimos para la didáctica de la traducción. Wilson (2004) sugiere que las herramientas representacionales se entiendan como un tipo de instrumentos de explotación de información que se manifiesta en distintos grados de desacoplamiento de las condiciones de funcionamiento dinámico y on-line. En ese continuo se encuentran las representaciones simbólicas, que pueden ser manejadas off-line en el aula y funcionan como instrumentos explicativos para aquellas tareas realmente "hambrientas" representacionalmente. De hecho, una parte fundamental del repertorio de acciones humanas es de tipo epistémico. Algunos instrumentos están diseñados y planificados para modificar la estructura informacional de nuestro entorno, para mejorar eficientemente la extracción y uso de información. Son, por lo tanto, de tipo cognitivo y epistémico. Estas herramientas no son solo exteriorizaciones que refuerzan y extienden los órganos del cuerpo humano, sino que a través de ellas el hombre se autoconoce. Son "órganos de la mente" y lo son del mismo modo en que las herramientas que usamos regularmente transforman la autopercepción de nuestro cuerpo. Así, estos órganos transforman nuestra autopercepción de las capacidades mentales; afectarían, dicho con otras palabras, a la imagen de nuestra mente. Por tanto contribuyen al desarrollo de la metacognición, ya que representan una prótesis transformadora de la estructura funcional de lo mental mismo. El defensor de la cognición situada podría objetar que hay formas de estar en el mundo que no implican representacio- 
nes desancladas y neutrales respecto a la acción, pero esto no quiere decir que no haya cierto tipo de tareas cognitivas que estén necesita. das de un tratamiento de la información en niveles más abstractos. Estas pueden pasar a estar disponibles de modo explícito con independencia del contexto en acción en que se manifiestan. Lo importante, sin embargo, es su evaluación constante para ajustar el éxito de los artefactos cognitivos con ciertas condiciones de fiabilidad y estabilidad en la ejecución de las tareas. Aquí converge el conocimiento declarativo con el procedimental como conocimiento para la acción y situación, y en ello debe basarse una pedagogía de la traducción literaria. La calidad de estos andamiajes epistémicos incide consecuentemente en la calidad de la fundamentación epistemológica de las estrategias de traducción en el aula.

La construcción de estos andamiajes epistémicos debe asentar sus bases en función de las siguientes premisas: a) las prácticas de traducción literaria deben estar mediadas por un contexto histórico-social; b) la cognición tiene lugar a través del cuerpo y la imaginación, incluyendo la cognición implicada en la traducción literaria; y c) la cognición está estrechamente vinculada a la enacción (Vega Encabo, 2005).

\section{ANDAMIAJES MEDIADOS POR EL CONTEXTO HISTÓ- RICO-SOCIAL}

En la traductología de corte funcionalista encontramos andamiajes que contribuyen tanto al aprendizaje de los distintos actantes implicados en el proceso y producto (Nord, 1988, 1997) como al aprendizaje de las normas de traducción. Contextualizar las normas literarias en función de las situaciones traslativas requiere detallar los encargos con variables tanto del proceso como del producto (según el modelo de normas preliminares, norma inicial y normas operacionales propuesto por Toury, 1995). Es esencial que el estudiante conozca asimismo el funcionamiento tanto del mercado de la traducción literaria para el cual va a trabajar como el papel de los distintos agentes (p.ej. las asociaciones profesionales). Ello contribuye al desarrollo de la competencia social y normativa del traductor literario. 
por otro lado, la competencia textual y pragmática del traductor liperatio viene apoyada por las aportaciones de la textología y pragmáif $\mathrm{i}_{\text {a }}$ que proporcionan artefactos epistémicos interesantes para la ingenjería textual: los criterios de textualidad (Beaugrande y Dressler, 1981), las intenciones comunicativas, los actos de habla, el acto textual, la macroestructura, las máximas de Grice (1978) y muchos otros. El objetivo pedagógico es crear modelos epistémicos del texto que contribuyan a la consecución optima de macro y microestrategias. En particular destacamos el modelo de Hatim y Mason $(1990,1997)$ con ${ }_{5} \mathrm{~s}$ dimensiones del contexto, ya que sirven para analizar con detalle el sentido que el texto transmite. La dimensión comunicativa configura la variación lingǘstica; la dimensión pragmática conforma la intencionalidad del discurso; y la dimensión semiótica hace referencia al sistema de valores de una determinada cultura. Su metodología es más elaborada y apropiada, bajo parámetros pragmáticos, para acometer el análisis (y traducción) de los textos literarios por su longitud y complejidad. De hecho, el modelo aborda con más profundidad que otros las posibles marcas textuales, haciendo hincapié en el tono, modo y campo textual, las implicaturas o las presuposiciones, entre otros aspectos. La óptima inferencia de estos aspectos debe asimismo ir apoyada por la adquisición del aprendiz de aquellos conocimientos necesarios sobre los estudios literarios que complementen la fundamentación metacognitiva de las inferencias textuales y pragmáticas, en función del tipo de texto y autor literario que esté traduciendo en un momento dado. Huelga nombrar la importancia de establecer una tipología textual, más o menos extensa en función del perfil y temporalización de contenidos impartidos según los grados y másteres universitarios de especialidad en traducción literaria, que abarque los géneros y tipos textuales más representativos vinculados a la narrativa, líríca y drama, a modo de prototipología textual (cf. SnellHomby, 1988). Los tipos de textos presentan convenciones de distinta índole y en distintos estadios que el estudiante debe conocer, ya sea a través de la documentación, de textos paralelos o de andamiajes explícitos proporcionados por el profesor. Si bien la construcción del significado es emergente e impredecible, hay estructuras que muestran patrones de regularidad y predecibilidad. Los estudiantes desconocen 
estos aspectos, por ejemplo, cómo construir los diseños textuales meta en función de sus regularidades e irregularidades.

\subsection{ANDAMIAJES MEDIADOS POR LA IMAGINACIÓN, CORPOREIZACIÓN Y COGNICIÓN}

La lingǘstica cognitiva dispone de andamiajes óptimos relacionados con la cognición corpórea, gestáltica, ecológica e imaginativa que caracteriza al ser humano. La traducción literaria no queda obviamente exenta de estas cuestiones cognitivas. Si la adquisión de la metacognición en el aula comprende dos dimensiones interactivas, es decir como conocimiento de las operaciones mentales y como autorregulación de las mismas (Burón Orejas, 2006), debemos incorporar aquellas teorías cognitivas que describan eficazmente el funcionamiento de la mente en el marco de estas dos dimensiones básicas. En este sentido, destacamos por ejemplo la teoría sobre la integración de espacios (conceptual blending) de Fauconnier y Turner (2002). Estos autores proponen la noción de «espacio mental» en relación con el funcionamiento interactivo de la conciencia humana y la interpretación textual y lingüística. Esta teoría proporciona una explicación plausible sobre el funcionamiento de la mente en relación con la percepción, imaginación y conceptualización. Su metodología nos serviría para evaluar con detalle y viabilidad los procesos mentales de los estudiantes cuando traducen, ya que los modelos previos de análisis del proceso aún son incompletos (Nord, 1988; Hönig, 1997; Bell, 1991).

En estrecha relación con la teoría de los espacios mentales incluimos la utilidad de otros enfoques cognitivos que describen eficazmente cómo organizamos, construimos y traducimos los conceptos según determinados efectos de prototipicidad (Rosch, 1978), según algunos principios de categorización subyacentes (Lakoff, 1987) y según los perfiles y bases en la configuración dinámica de dominios cognitivos que condicionan la emergencia del significado en la acción (Langacker, 1987). Todo ello se complementaría con la teoría cognitiva de la metáfora y metonimia, tan útil para enriquecer la autorreflexión sobre los procesos mentales implicados en su construcción. En este sentido destacamos el papel que representan las metáforas orientacionales, 
conceptuales, de imagen y de forma en la obra y traducción de un autor literario específico. Respecto a la metonimia, destacamos los interesantes trabajos realizados por Ruiz de Mendoza (2002) en estrecha relacion con la percepcion humana de la realidad y que determinan la eleccion y escritura de las distintas formas lingüísticas.

\subsection{LA COGNICIÓN MEDIADA POR LA ENACCIÓN}

La teoría cognitiva del aprendizaje estudia cómo los sistemas son capaces de guiar sus acciones en situaciones locales. Así, la cognición dependerá del carácter corporeizado de las aptitudes sensoriomotrices que, a su vez, están inmersas en un contexto biológico, psicológico y cultural más amplio. Enacción se entiende en este sentido como el "aprendizaje en acción», puesto que la acción desempeña un papel crucial en los procesos cognitivos y perceptuales. La función que desempeñan en este sentido los artefactos manuales (las herramientas informáticas), sensoriales (las manos, la vista, el oído), cognitivos (la memoria individual y extendida por la cooperación de agentes, la atención, las emociones, los procesos controlados e incontrolados, las automatizaciones, la creatividad, el razonamiento, las creencias, la idiocultura) o lingüísticos, determinarán el contenido y modo de aplicación de los distintos andamiajes proporcionados para el aprendizaje de la actividad traslativa literaria. Por ello, los artefactos epistémicos anteriormente descritos deben entenderse siempre como apoyos del saber para la acción, y están en función de la adecuación personal e individualizada del usuario. Su aprendizaje y acoplamientos óptimos con las extensiones de la mente en el contexto y situación de traducción depende de cómo se gestionen teniendo en cuenta el perfil de los estudiantes. Hablamos en este sentido de algunas tareas cognitivas que necesitan de un tratamiento de información en niveles más abstractos (top-down), ya que pueden pasar a estar disponibles de modo explícito en un momento dado (saber que) con independencia del contexto en acción en que se manifiesta. La cuestión principal es su evaluación constante para ajustar el éxito de los artefactos cognitivos, sensoriales, manuales y lingüísticos con ciertas condiciones de fiabilidad, confianza y estabilidad en la ejecución de las tareas (saber cómo). En la 
traducción literaria, estos andamiajes más abstractos son muy necesa. rios porque, si son adecuados, ayudan al estudiante a descubrir sus propias verdades metacognitivas.

La manera de evaluar estos andamiajes, sin menospreciar la importancia de los métodos cuantitativos para tal fin, debe incorporar en un estadio inicial la investigación de aquellos enfoques de corte cualitativo adecuados para el aprendizaje optimo de la traducción literaria, ya que se trata de evaluar principalmente la introspección vs. metacognición, dada la gran complejidad de esta modalidad de traducción. En este sentido destacamos la importancia del pensamiento narrativo en la argumentación de los propios procesos mentales y en la argumentación de las causas por las que se ha elegido una determinada estrategia traslativa. De hecho, el método de investigación cualitativo se emplea para conocer procesos complejos relacionados con la captación e interpretación subjetivas (Sevillano García, 2005: 209-210), cuya recogida de datos se hace mediante procedimientos abiertos como el storytelling, la narratología, las field notes, el cuestionario de preguntas abiertas o el comentario de traducción. La valoración de estos datos registrados tiene lugar muchas veces en forma de análisis interpretativo de documentos que se centran en la descripción y comprensión de los comportamientos individuales de los sujetos, en el marco de un análisis de la realidad contemplada en su totalidad (visión holística), matizada por la visión personal de los individuos implicados, analizando sus creencias, pensamientos, intenciones o motivaciones (sobre la aplicación narratológica del cuestionario de preguntas abiertas en relación con la fundamentación de estrategias traslativas realizada por estudiantes, véase García Álvarez 2011; sobre el andamiaje del comentario de traducción véase García Álvarez 2007). 


\section{ABORDANDO CUALITATIVAMENTE ALGUNAS ESTRA- TEGIAS TRASLATIVAS: UN CASO DE ESTUDIO}

Una vez planteado el retorno a la introspección y descritos los andamiajes epistémicos que podrían sustentar una didáctica de la traducción literaria, a continuación intentaremos ilustrar algunos puntos de la teoría expuesta a través de un caso práctico. El objetivo inmediato no es ofrecer una unidad didáctica finita a modo de receta, sino describir una serie de estrategias traslativas extraídas del mundo profesional, analizarlas desde el punto de vista cognitivo y esbozar su abordaje cualitativo en el aula. El texto elegido a modo de ejemplo pertenece a una traducción real del alemán al español llevada a cabo en el ámbito profesional y, dada su corta extensión, podría fácilmente ser trasladado a un entorno didáctico. Siguiendo la premisa de que las prácticas de traducción literaria están mediadas por un contexto histórico-social, comenzaremos situando en él tanto el texto origen (TO) como el texto meta (TM). En segundo lugar, ya en el plano de la imaginación, corporeización y cognición, argumentaremos algunas estrategias condicionadas por el papel de la percepción y la imagen, los dominios cognitivos y los prototipos en la construcción conceptual. Asimismo abordaremos brevemente la traducción de la metáfora. Respecto a la cognición mediada por la enacción, presentaremos un modelo de andamiaje cuyas variables posibilitan la fundamentación de las estrategias de traducción literaria de los estudiantes.

\subsection{CONTEXTO HISTÓRICO SOCIAL}

No cabe duda de que toda estrategia traslativa se ve directa o indirectamente influenciada por el contexto histórico-social que rodea al TO. Prueba de ello es que la escasa bibliografía existente sobre didáctica de la traducción literaria coincide en subrayar la necesidad de que el alumno se familiarice con el contexto que rodea al autor y la obra que va a traducir. El fragmento que nos ocupa está extraído de la novela 
Wadzek contra la turbina de vapor, de Alfred Döblin (1878-1957). Consideramos que en el marco de este artículo el autor no requiere mayor presentación - necesidad que obviamente si se plantearía en el aula , si bien destacaremos algunos rasgos de su personalidad literaria muy relevantes de cara a la traducción, en lo que concierne a las expectativas que ésta despierta. Como se explicará a continuación, este parámetro también puede afectar a las estrategias traslativas; sin embargo, esto rara vez se contempla en los enfoques tradicionales sobre didáctica de la traducción literaria, todavía más centrados en el TO que en el TM, circunstancia ya superada en otros ámbitos de la teoría de la traducción, incluso en el ámbito literario, con los trabajos de la Escuela de la Manipulacion, entre otras corrientes.

En palabras de Miguel Sáenz (2002:9), Alfred Döblin es «el gran renovador de la novela de los años veinte» $\mathrm{y}$ "uno de los escritores más insólitos de la literatura universal", una figura controvertida y todavía hoy un autor semimaldito que no acaba de encontrar su puesto en la literatura, ni siquiera en la literatura alemana. Se trata por tanto de un autor con fama de complejo, conocido principalmente por la que se considera su obra cumbre, Berlin Alexanderplatz (1929). Wadzeks Kampf mit der Dampfturbine fue publicada en 1918; es la obra que inaugura un ciclo dedicado a Berlín (Berliner Romane) y algunos expertos la consideran una precursora (fallida o no) de Berlin Alexanderplatz (Gong, 2003: 302), si bien es mucho menos sórdida, más transparente y cercana que la novela döblinesa por antonomasia. Cuenta la historia de Franz Wadzek, un empresario que se arruina, pierde la cabeza y los nervios y comete toda serie de dislates porque, además, vive en un mundo de especulación y valores huecos dentro de un círculo familiar muy cerrado, pero muy falto de autenticidad. En lo que respecta a su recepción, tanto el momento de ser publicada como en la actualidad, la obra nunca ha estado exenta de polémica, puesto que las opiniones están divididas entre quienes la consideran uno de los máximos exponentes del expresionismo literario y quienes la definen como, cuando menos, extraña. Lo cierto es que el libro sugiere y requiere varias lecturas para ser abarcado en toda su complejidad (Riley, 1987: 375), razón por la cual se nos antoja especialmente apto para ser abordado desde un punto de vista cognitivo. Todo esto no es obice para que, al mismo tiempo, la novela esté estrechamente vincu- 
lada al contexto historico y programa estético según el cual fue concebida. Así, en cumplimiento estricto de los mandamientos expresionistas y la corriente conocida como Neue Sachlichkeit (Nueva Objetividad), la novela está llena de prolijas descripciones de personajes cosificados y objetos personificados, los cuales contribuyen a articular el humor negro y grotesco que entrevera toda la obra. La ironía también interviene en su sentido más alemán, es decir, como mecanismo de distanciamiento crítico: lo que se persigue es la ruptura de la identificación a través de figuras retóricas como la hipérbole. Asimismo, es importante destacar el uso de la técnica de montaje, que combina todos los medios estilísticos (repetición, monólogo interior, discurso vívido, ruptura sintáctica, cambios de perspectiva, presentación simultánea, etc.) y del lenguaje cinematográfico. En el fragmento elegido se condensan a la perfección algunos de estos rasgos, que dotan a la escena de un valor paradigmático a la hora de describir la prolija manera de mirar y de representar que tiene Döblin. A falta del texto completo, esbozaremos el contexto inmediato del fragmento a fin de que el lector valore mejor su función.

La señora Wadzek, personaje que Döblin muestra bajo un prisma negativo tanto en lo físico como en lo psíquico, se dispone a preparar café para su marido quien, a su vez, espera en el salón abatido, agotado y en silencio tras fracasar en el intento de llamar la atención de la policía. No hay diálogo alguno entre los cónyuges, desconocemos qué pasa por sus cabezas, pero a través del comportamiento de la señora Wadzek mientras prepara el café se masca una tensión que estallará en cuanto uno de los dos articule palabra. A continuación reproducimos original y traducción de la escena:

"[Frau Wadzek] Sie ließ die Küchentür offen; stampfte zwischen Spind und Herd; Herdeinsätze polterten auf dem Steinboden, wurden mit übertriebener Erregtheit wieder gegen ihre Haken gestoßen. Wasser sprudelte aus der Leitung in den Kaffeekessel; als der Kessel über dem Feuer zu singen anfing, drehte Frau Wadzek dicht an der Tür auf einem Schemel die Kaffeemühle; das Knacken, Brummen, Knattern dauerte drei Minuten. Das dampfendheiße Wasser warf seinen Deckel ab. Brühend wurde es ausgegossen über das braune Kaffeepulver, das die Frau in einen blaubemalten vierkantigen Topf ausgeschüttet hatte. Der Haufen des Pulvers, der größte, ballte sich 
nach einigem Schwanken am Boden des Topfes zusammen; ein anderer wirbelte, von großen Blasen hochgeführt, an der Oberfläche, bildete eine dünne Schicht, wie ein Moor, das durch platzende Blasen von unten durchbrochen wurde. Mit groten Stöken durchwatete Frau Wadzek den Raum, rechts eingeengt vom Herd und Küchenspind, links vom Küchentisch; die schmale Gasse, die am Fenster endete, am Schemel begann, durchschwamm unermüdlich die Frau, die ihre Waffen rüstete. Über dem offenen Herdfeuer erhitzte sich die Luft; der Wasserdampf, der aus dem viereckigen blaubemalten Topf hauchte, verbreitete sich. Thre Wallfahrt beendend, hing die Brauerin ein kleines dichtes Metallsieb in eine bauchige Kaffeekanne; der Hals des porzellanenen Apparats war abgebrochen, auch ragte es deckellos in die Luft. Dadurch fehlte dem Ganzen der Abschlu1; der Bauch der Kanne ein guter Vorsatz, aber das Geheimnis der Kanne ließ sich nicht bewahren. Aus dem viereckigen Reservoir rann der schwarze Extrakt, körnchenbeladen, in den bauchigen Behälter; das Sieb schützte die Kanne; wie ein Netz fing es die gequollenen Stückchen ab; der Rest blieb in dem viereckigen Reservoir als pappiger Schlamm liegen, während die Kanne in mütterlicher Bewegung den reinen guten Saft annahm und umschloB."

"[La señora Wadzek] Dejó abierta la puerta de la cocina y se puso a trajinar pesadamente entre el fogón y la alacena. Las placas cayeron al suelo con gran estrépito y las colgó de nuevo en los ganchos correspondientes con un nerviosismo desmesurado. El agua borbote6 del grifo al hervidor. Cuando este empezó a silbar una vez puesto al fuego, la señora Wadzek, sentada en un taburete próximo a la puerta, estaba girando la manivela del molinillo de café. Los chasquidos, rugidos y crujidos duraron tres minutos. El vapor levantó la tapa. El agua hirviendo fue vertida sobre el polvo marrón que la mujer había volcado en un cacillo cuadrangular pintado de azul. Aquel montón de polvo, el más grande, se acumuló en la base del cacillo tras sufrir cierto vaivén; arrastrado por grandes burbujas, otro montón se arremolinaba en la superficie formando una fina capa, como una ciénaga perforada desde el fondo por el estallido de varias burbujas. La señora Wadzek vadeaba el espacio a empujones, viendo constreñidos sus movimientos por el fogón y la alacena de la derecha y la mesa de la izquierda. Mientras preparaba sus armas, la mujer surcaba incansable el estrecho pasadizo que finalizaba en la ventana y comenzaba junto al taburete. El aire que circulaba sobre el fogón abierto se calento; el vapor que emanaba del cacillo azul y cuadrangular se expandía. Como colofón a su peregrinaje, la hacedora de café colocó un pequeño filtro metálico en una cafetera tripuda. El cuello de porcelana se había partido y, 
además, el artefacto se erguía destapado. El conjunto, por tanto, careda de cierre; su redondez era un buen comienzo, pero insuficiente para guardar el secreto de aquella cafetera. El extracto negro y granuloso fue manando desde su deposito cuadrangular hasta el recipiente tripudo; el filtro protegía la cafetera y capturaba los pequeños grumos como si fuese una red. Los posos se quedaban en el cacillo, donde formaban un fango espeso mientras la cafetera acogía el caldo puro y gustoso y lo abrazaba en su seno."

Antes de pasar al nivel de las microestructuras, no queremos finalizar este apartado macroestructual sin aludir al contexto históricosocial del TM, pues como hemos avanzado y expuesto en la parte teórica, opinamos que factores como las características del mercado editorial o las normas de traducción pueden influir a la hora de aplicar una determinada estrategia traslativa. En el caso de la obra que nos ocupa, la traducción se realiza para una editorial que puede calificarse de joven, audaz y minoritaria, ya que fue creada en 2007 con la voluntad de recuperar clásicos incontestables, pero también para «fabricar» clásicos modernos. Uno de los rasgos distintivos de la calidad de los numerosos pequeños sellos que han surgido en España en los últimos años es el esmero que ponen en todo lo relacionado con la traducción, cuya prueba más visible, en el sentido literal del término, tal vez sea el hecho de que el nombre del traductor aparezca en la portada de todos los libros. Amén de subrayar factores tal vez más prosaicos, pero no por ello menos importantes desde un punto de vista práctico y rara vez abordados desde la didáctica, como una tarifa y unos plazos razonables, lo más destacable es la posibilidad de incluir algún tipo de paratexto en la traducción. Con ello no nos referimos tanto a la consabida "Nota del traductor", que unos consideran un salvavidas y otros una especie de capitulación, sino más bien a algún tipo de comentario (nota introductoria del traductor, prólogo, epílogo, etc.) que ayude a los lectores, interesados ya de por sí al tratarse de una obra y un autor minoritario, a enmarcar un texto que, desvinculado de su contexto y propósito original, podría tener un efecto bumerán sobre la traducción. Postulamos que, en circunstancias ideales, este tipo de decisiones han de ser negociadas y tomadas de manera conjunta entre el traductor y el editor, además de ser contempladas en el aula. En el caso concreto de este fragmento no ha sido necesaria ninguna nota del traductor, pero sí se da la circunstancia de 
que en el prólogo de la traducción, obra de la propia traductora, se alude al carácter paradigmático de la escena (Santana, 2011: 11).

En conclusión, esperamos que este ejemplo ilustre la importancia de llevar las competencias social, normativa, textual y pragmática al aula de traducción literaria, ya que por un lado ayudan al estudiante a contextualizar y cimentar sus decisiones $y$, por otro, tienen un fiel reflejo en la práctica, en especial ahora que las titulaciones buscan distinguirse por su carácter "profesionalizante».

\subsection{IMAGINACIÓN, CORPOREIZACIÓN Y COGNICIÓN}

Son muchos los rasgos microestructurales del fragmento propuesto que podríamos analizar, por ejemplo la personificación, el uso de verbos onomatopéyicos, la aliteración, la puntuación, etc.; sin embargo, nos vamos a centrar en aquellos que revisten especial interés desde un punto de vista cognitivo. En concreto nos referiremos a los prototipos, los dominios cognitivos, las metáforas y el símil, que en realidad es producto de operaciones mentales del traductor basadas en la analogía. Todo ello condiciona el significado emergente del texto.

Como se ha expuesto en la parte teórica, el traductor literario representa, esboza y extrae continuamente imágenes cuando traduce. Según la teoría cognitiva, dichas imágenes se construyen a partir de prototipos y conllevan a su vez la representación dinámica de determinados dominios cognitivos o estructuras de conocimiento (Langacker, 1987). En la escena seleccionada, un claro prototipo es el café y el acto de prepararlo. A nadie se le escapa que la imagen mental que uno dibuja cuando piensa en la palabra café difiere no sólo entre culturas ni entre lenguas, sino también entre individuos. En la combinación linguística y cultural aquí tratada, alemán-español, es también un hecho que las asociaciones que el café despierta en una y otra cultura son distintas: en Alemania el prototipo es el café de filtro, que se sirve principalmente solo o con crema, mientras que en España suele ser un café más intenso, casi siempre preparado en una cafetera exprés y servido de múltiples maneras. Este prototipo tiene su reflejo en el 
lenguaje. Vemos como en la detalladísima descripción de la escena que gira exclusivamente en torno al café, Döblin utiliza palabras propias de ese dominio cognitivo, como Kaffeekessel, Kaffeemühle, Kaffeptulver, Brauerin, (Metall)sieb, (Kaffee)kanne, Extrakt, o körnchenbeladen. Aunque en España también hubo una época, proxima a la de la novela, en la que se hacía café moliéndolo previamente, y por tanto no resulta una asociación tan ajena, creemos que el traductor de hoy y el lector de hoy no tienen un vínculo tan directo con un objeto como puede ser el hervidor (Kaffeekessel), que con la especificidad propia del alemán Döblin denomina hervidor de café. En la traducción se ha optado por omitir dicha especificación, de café ya que en la lengua de llegada no es tan frecuente esa denominación. Otro término característico que refleja otro dominio cognitivo solapado con el anterior en la representación mental de la escena lo constituye Brauerin, que procede del verbo brauen, referido principalmente a la fabricación de cerveza; sin embargo, en segunda acepción, este verbo es el que se utiliza como sinónimo de preparar una bebida (normalmente café, té o infusiones) a partir de una sustancia sobre la que se vierte agua caliente. El sustantivo por tanto habla por sí solo en el contexto y se refiere a una mujer experta, en este caso, en preparar café. Es evidente que el español carece de un término equivalente, de modo que aquí se ha optado por parafrasearlo como hacedora de café. Es un término sin duda mucho menos rico y directo que el original, pero creemos que, puestos a crear en español un término, otra opción más próxima al original como cocedora o preparadora de café habría llamado en exceso la atención del lector, produciéndole una extrañeza que atentaría contra la pragmática textual. Por otro lado, opciones más idiomáticas como encargada restarían parte del componente mecanizante que tiene la escena. Nótese que no es nuestra intención aquí justificar decisiones de traducción concretas, sino valorar distintas estrategias (todas ellas posiblemente válidas) a la luz del enfoque cognitivo. Por último nos gustaría destacar el adjetivo körnchenbeladen, que el autor/narrador crea a partir de la gran capacidad compositiva del alemán (körnchen = literalmente granitos + beladen $=$ cargado de); en este caso se ha optado por el adjetivo granuloso, porque creemos que una opción literal habría restado legibilidad al texto y que el adjetivo elegido ya posee una considerable fuerza expresiva. Basten estos ejemplos para ilustrar que tra- 
ducimos imágenes dinámicas expresadas mediante palabras que connotan significados emergentes, razón por la cual los diccionarios -en cuya defensa recordaremos que no fueron concebidos para traductores-, son herramientas necesarias, pero no suficientes. Es más, son precisamente palabras como hervidor/Kessel las que muchos traductores, habiendo estado inmersos en la cultura de partida, siguen usando en alemán aunque hablen en español, en parte por pereza mental, pero también por la relevancia imaginativa que tienen en cada lengua.

En segundo lugar quisiéramos hablar de las metáforas. No es nuestra intención hacer un recorrido por los distintos tipos de metáforas que impregnan el fragmento, que sin duda requeriría mucho más espacio en el presente artículo, pero sí comentar alguna de las metáforas de imagen y de forma que aparecen. Empezaremos por los verbos durchwaten y durchschwimmen y por el sustantivo Wallfahrt, puesto que están relacionados. A pesar del ajetreo que destila toda la escena, ya que la señora Wadzek no deja de moverse de un lado para otro (circunstancia que recoge por ejemplo el verbo trajinar), sabemos, por una descripción anterior, que la señora Wadzek es tremendamente grande y gruesa, lo que diríamos una mole que no se caracteriza precisamente por su gracilidad. A la hora de describir sus movimientos en esta escena, Döblin utiliza verbos metafóricos relacionados con el agua, como son durchwaten (vadear) y durchschwimmen (literalmente atravesar a nado), para dar la sensación de algo pesado que avanza lentamente. En español se ha optado por mantener la metáfora de forma recurriendo a los verbos vadear y surcar. Del mismo modo, el autor califica toda la acción de Wallfahrt, en español peregrinación. En la traducción, la metáfora se mantiene de nuevo (y se ve incluso enriquecida por todas las asociaciones religiosas que conlleva en español), si bien bajo la forma peregrinaje, para evitar cacofonías con la palabra colofón. En este punto puede ser interesante detenerse en el porqué de este colofón, que no aparece como tal en el original, donde dice literalmente terminando o para terminar. Un ejercicio de introspección nos lleva a pensar que hemos recurrido al uso de colofón para recalcar el carácter de ritual y la importancia que el autor está dando a toda la escena por el hecho de describirla con tanto detalle -como hemos dicho, se trata de uno de los rasgos propios del expresionismo-. Además de la metáfora de preparar las armas, que funciona en ambos idiomas y con la cual 
el autor expresa la tensión casi bélica ya mencionada en la contextualización de la escena, el fragmento finaliza con la descripción, de nuevo prolija, de la forma de la cafetera y su Bauch, en español tripa o barriga. Döblin no s6lo utiliza el sustantivo Bauch y repite el correspondiente adjetivo bauchig (barrigudo o tripudo), sino que, a través del adjetivo mütterlich (maternal), concluye describiendo la cafetera como una madre que acoge y abraza el caldo puro y gustoso, es decir, el café. Con la idea de mantener la metáfora de la madre, en español se ha optado por la construcción lo abrazaba en su seno. Una última metáfora que quisiéramos comentar es la que se utiliza una vez más para dar importancia a toda la acción y dotarla incluso de un halo de misterio. El autor quiere describir a toda costa lo que ocurre dentro de la cafetera, intenta que nos metamos en su interior, pero no llega a descubrir su secreto: "su redondez era un buen comienzo, pero insuficiente para guardar el secreto de aquella cafetera». En este caso, creemos que la traducción debe ser capaz de transmitir ese misterio y esa tensión que tanto el lector del original como de la traducción deben encargarse de completar a partir de la imagen que construyan en su mente. Dicho en otras palabras, la traducción no debe explicar, sino tratar de sugerir los efectos imaginísticos del original.

Queremos cerrar este apartado con un simil, puesto que también se trata de una construcción mental basada en la analogía y directamente relacionada con imágenes mentales. En este caso la superficie del café se compara con «una ciénaga perforada desde el fondo por el estallido de varias burbujas"; más adelante se habla de los restos de café que quedan en el cacillo como "un fango espeso». Es evidente que, a la hora de establecer un símil, recurrimos a imágenes mentales que le sean familiares a nuestro receptor para establecer relaciones incluso más directas que en la metáfora, donde la relación entre uno y otro elemento no se explicita a través de un es como. Una vez más, dichas imágenes no siempre tienen que coincidir en las distintas culturas, 0 al menos no en la misma medida. Esto es lo que ocurre con el campo semántico en el que se enmarcan las palabras Moor, pantano 0 ciénaga, y Schlamm, barro, lodo, fango. Puede que en este caso el campo semántico no esté tan activo en español, pero la relación entre la textura y el color del café con palabras como ciénaga y fango sin duda se mantiene. La labor del traductor, consciente o inconsciente, es de nue- 
vo dibujar en su mente la imagen, en este caso del símil, y encontrar una imagen que re-produzca el mismo efecto. No se trata tanto de adaptar, sino de encontrar el equilibrio justo entre la relación cogniti. va que se establece entre los dos términos y la extrañeza y originali. dad del símil como tal. Es aquí donde el elemento creativo desempeña un papel fundamental, cuyo análisis podemos abordar desde el punto de vista de la cognición.

\subsection{COGNICIÓN MEDIADA POR LA ENACCIÓN: EL CO. MENTARIO TRASLATIVO}

Risku (1998:112) corrobora la idea de que la verbalización metacognitiva constituye un importantísimo recurso que contribuye no sólo al desarrollo y evaluación de las competencias y estrategias traslativas concretas que tienen lugar en la traducción de un texto, sino también al desarrollo del componente social de la actividad experta. En este sentido, el comentario de traducción constituye un andamiaje ótimo para diseñar ciertas pautas metodológicas que guíen al alumnado en la fundamentación por escrito de las estrategias. El objetivo didáctico final es analizar cómo los estudiantes complementan el conocimiento declarativo y procedimental, y ver si la verbalización adecuada y consciente del primero contribuye a la optima consecución del segundo durante la acción traslativa o viceversa.

$\mathrm{Al}$ objeto de que el estudiante pueda actuar libremente en la fundamentación de sus estrategias traslativas y el docente pueda observar de una manera más viable la propia introspección del proceso de cada estudiante, cabe señalar que las pautas que a continuación se expresan deben ser concebidas únicamente como una orientación para el alumnado que le sirva para planificar, organizar y desarrollar por escrito el comentario traslativo. Si el estudiante decide no someterse a las pautas establecidas y desea ceñirse a las suyas, el docente debe entender que este hecho es perfectamente legítimo, puesto que cada sujeto, en el proceso de aprendizaje, recoge el conocimiento declarativo y procedimental que más le conviene en función de su idiosincrasia. Por otro lado, la flexibilidad del comentario permite al docente observar los aciertos y errores de la metodología aplicada en las clases 
de traducción. Los modelos cognitivos sobre el proceso siempre pueden mejorarse y perfeccionarse, por lo que deberían quedar abiertos a cualquier crítica y correccion de sus postulados.

A continuación expondremos la visualización general del comentario traslativo, con la finalidad de ir describiendo cada una de las pautas aplicándolas al ámbito de la traducción literaria y al fragmento textual presentado. Si bien en un entorno didáctico real es deseable abordarlas en su conjunto, veremos cómo no todas las pautas propuestas tienen la misma relevancia en nuestro ejemplo, de modo que nos ceñiremos a las más relevantes. Cabe por último puntualizar que este modelo de comentario constituye tan sólo uno de los múltiples modelos posibles para evaluar el proceso de cada estudiante en los exámenes de traducción, en las traducciones individuales o en equipo. Habida cuenta de su nivel de dificultad, el comentario traslativo del fragmento elegido presupone un nivel competencial alto, como el que adquieren alumnos de los últimos cursos de Grado o Máster y, en el mejor de los casos, enmarcado en una asignatura específica de traducción literaria.

El alumno recibirá por escrito las siguientes instrucciones:

\section{COMENTARIO TRASLATIVO:}

Para evaluar su traducción de la manera más objetiva posible, deberá realizar un comentario descriptivo general en el que se comentarán las dificultades más importantes y se fundamentarán, desde las variables que a continuación se expresan y que usted considere más relevantes, las soluciones aportadas. No tiene por qué contestar a cada una de las pautas. Puede fundamentar el comentario como usted quiera; estas pautas tan sólo representan un modelo orientativo que puede servirle para planificar y organizar sus argumentos y decisiones de un modo coherente:

1. Según las instrucciones traslativas del encargo (normas de traducción, normas textuales, etc.)

2. Según la macrofinalidad que se persiga con el TM (posibles diferencias respecto a la macrofinalidad del TO) 
3. Según las consideraciones y/o diferencias ideológicas, culturales e informativas entre los receptores del TM y del TO

4. Según las convenciones textuales del TM (normas según su tipología, lo que permite y no permite, diferencias con las del TO, etc.)

5. Posibles defectos del TO

6. Tiempo y lugar de publicación del TM (posibles diferencias temporales y locales con el TO en caso de que las hubiese)

7. Posibles problemas de redacción y de cualquier otra indole relacionados con las intenciones perseguidas en el TM, y posibles diferencias con respecto a las intenciones del TO (persuasiva, informativa, directiva, instructiva, expresiva)

8. Posibles cuestiones, diferencias y cambios en la estructura textual del TM respecto a la del TO (centrada en un tema, en un acto principal, estructura mezclada, etc.)

9. Posibles cuestiones y diferencias entre los actos textuales y actos de habla de ambos textos (según las máximas y las convenciones establecidas por cada cultura)

10. Posibles similitudes y diferencias entre las relaciones funcionales de las frases de ambos textos (incluyendo posibles omisiones, ampliaciones, paráfrasis, etc., y problemas relacionados con el determinado grado de explicitud e implicitud necesario para redactar la informatividad del TM teniendo en cuenta los principios de economía y relevancia)

11. Cuestiones y problemas léxicos y terminológicos: similitudes y diferencias conceptuales pragmático-cognitivas entre ambas situaciones comunicativas y en función de las diferencias existentes entre los receptores (exotización, domesticación; semántica de prototipos, proyecciones metafóricas, metonimicas e imaginisticas, scripts, categorias léxicas en función de las instrucciones traslativas, etc.) 
12. Cuestiones y problemas de estilo en el TM (registro lingüístico, dialectos, problemas relacionados con el campo, modo y tono/tenor, etc.)

13. Cuestiones y problemas de cohesión en el TM: problemas con las colocaciones, puntuación, rasgos suprasegmentales, relaciones de forma y significado entre las frases, estructura del tema-rema, etc.

14. Comentario sobre las fotos $u$ otros elementos no verbales, los subtextos y los elementos tipográficos en el TM (posibles diferencias con los del TO)

15. Posibles cuestiones o problemas de consulta en diccionarios, enciclopedias, textos paralelos, bases de datos, informantes, etc.

16. Posibles negociaciones con el cliente de la traducción y otros actantes del proceso

17. Problemas con el tiempo de realización de la traducción

18. Otras consideraciones que crea oportunas (p.ej. fundamentaciones basadas en el conocimiento declarativo: traductología, teorias interdisciplinares, etc.)

El orden de las pautas establecidas (1 a 14) pretende orientar al estudiante a que fundamente de una manera interactiva sus estrategias desde los procesamientos de más alto nivel hacia los de más bajo nivel. No se trata de contestar a cada pauta según el orden establecido, sino de una manera flexible y dinámica, con la interacción de las que considere más relevantes, como resultado del carácter espiral del proceso.

Las pautas 1, 2, 3 y 4 están referidas al encargo de traducción en un sentido amplio, puesto que sus instrucciones traslativas representan el punto de partida para planificar la macroestrategia y macrofinalidad del TM (determinantes para las microestrategias), aplicar el criterio de aceptabilidad al TO y al TM y fijar las llamadas normas de traducción en el ámbito literario (cf. Toury 1995). El hecho de explicitar información adicional en dichas pautas tiene el cometido didáctico de que el estudiante fije su atención en todas las instrucciones del encargo, en- 
tienda y aplique el concepto de política traslativa. El aprendizaje de la llamada competencia normativa aún constituye un campo poco estudiado en el ámbito literario, y sin embargo tan necesario para la didáctica de la traducción, ya que -tal vez excepción hecha de la llamada literatura de género- el estudiante no suele estar familiarizado con las normas de traducción en el mercado nacional e internacional. En este grupo de pautas también se concibe, por ejemplo, la posibilidad de incluir notas del traductor y cuáles son sus convenciones según el TM. En nuestro ejemplo sería interesante explicitar en el encargo algún dato referido al contexto histórico y social no sólo del TO, sino también y sobre todo del TM, expuestos en el punto 3.1. De ese modo, el estudiante puede reflexionar sobre si el hecho de que la novela de Döblin se publique en una editorial minoritaria, que apuesta por obras de calidad dirigidas a un lector interesado hace, por ejemplo, que el TM soporte mejor o peor las notas del traductor.

Si bien no suele ser siempre el caso ni afecta directamente al fragmento presentado, nos permitimos detenernos brevemente en la pauta 5 sobre posibles defectos comunicativos del TO, pues cobra especial relevancia si la aplicamos al conjunto de la novela y nos sirve para ejemplificar cómo las pautas del comentario deben aplicarse de forma dinámica y flexible. Es importante aclarar que la novela fue escrita de un tirón entre agosto y diciembre de 1914, pero no vio la luz hasta cuatro años después. Esto se debió no sólo a los efectos de la guerra, sino a las duras críticas que en 1915 recibió el manuscrito, que llevaron a Döblin a realizar numerosos cambios y correcciones. Dichos cambios son en su mayoría omisiones que pretenden aligerar el estilo y conferirle más viveza, si bien en no pocas ocasiones ponen al traductor en el brete de explicitar conexiones que en algunos casos ha de deducir, en otros presumir y, a lo peor, intuir con el fin de desentrañar los puntos oscuros del original, que pueden llegar a interpretarse como errores del TO. Nos referimos especialmente a la omisión de referencias temporales y locativas que complican las labores de interpretación de un texto en el que los personajes se caracterizan por un comportamiento no precisamente convencional. En el caso de esta traducción, se disponía de varias versiones del TO. Si trasladamos este ejemplo al aula, sería interesante aportar este dato en el encargo a fin de ilustrar la importancia de documentarse sobre las circunstancias 
que rodean al TO, desentronizar hasta cierto punto el original y familiarizarse con el tratamiento del error en traducción literaria.

En lo que respecta a la pauta 6, relacionada con las diferencias temporales y locales entre ambos textos, permite analizar omisiones 0 modificaciones necesarias en el TM vinculadas a estos parámetros. Este factor posibilita evaluar, por ejemplo, si el alumnado se ha percatado de que el tema interno del TO es actual o está desfasado, hecho que implicaría modificaciones o ampliaciones en la informatividad del TM. En el caso que nos ocupa, esta circunstancia remite por ejemplo a la necesidad o no de plantear un prólogo, propuesta que en la vida real suele correr a cargo del traductor. Por otro lado, también sería interesante tematizar en el aula cómo el sistema literario de llegada en el que se inserta el TM influye en la recepción de la obra. En el caso de Wadzek contra la turbina de vapor, ocurre por ejemplo que en el contexto de crisis económica actual que ha rodeado la publicación del libro, ha sido precisamente el aspecto económico (ascenso y caída de un fabricante) el elegido para promocionar la novela y el más destacado por la crítica, si bien no es el aspecto predominante de la obra en su conjunto.

Las pautas 7, 8, 9 y 10 comprenden principalmente los aspectos pragmáticos del texto (intenciones, estructura textual, principios conversacionales, etc.). Hacen por tanto referencia a cuestiones ya descritas en 3.2., como analizar el valor pragmático y cultural de una situación como la de preparar el café. Asimismo, es importante subrayar la importancia de los aspectos pragmáticos al traducir un estilo tan particular como es el expresionismo. Los alumnos no sólo deben conocer y reconocer los rasgos que caracterizan esta corriente estilistica en ambas culturas, sino saber re-crearla en un contexto histórico y social determinado. Tal y como se ha dicho en el prólogo a la novela, Döblin logra elevar la extrañeza al grado de arte, ser coherente en su incoherencia. Reproducir esta característica a la luz de las circunstancias que rodean el encargo de traducción es el reto al que nos enfrentamos.

Las pautas 11, 12 y 13 bajan un peldaño más en la escalera hacia la concreción. En este nivel, el alumno podría aplicar sus conocimientos sobre lingüistica cognitiva (prototipos, dominios cognitivos, construcción de metáforas y símiles), tal y como se ha recogido en el punto 3.2 . 
También se abordarían aquí cuestiones relacionadas con el registro lingüístico y el estilo textual del TM, por ejemplo en lo que respecta a la traducción de dialectos (aspecto que también aparece en la obra de Döblin, aunque no se recoge en este fragmento). Cabría asimismo tematizar el trabajo con textos paralelos -o más bien lecturas paralelas-, un aspecto apenas tratado en didáctica de la traducción literaria. Finalmente, se abordarían problemas o comentarios generales sobre la cohesión del TM, así como aspectos formales: estructura tema-rema, relaciones de forma entre las frases del TM o cuestiones de puntuacion, ortografía y rasgos suprasegmentales.

La pauta 14 alude a cualquier elemento no verbal (fotos, dibujos, etc.) implicado en el TO que necesite ser comentado en relación con su función textual específica en el TM. Esta pauta no es de aplicación en el texto elegido, pero sí podría tener relevancia en otros géneros en los que la ilustración desempeña un papel fundamental, como puede ser la literatura infantil y juvenil o un género tan de moda $-y$ por tanto susceptible de despertar el interés de los alumnos- como es la novela gráfica.

Las pautas 15, 16, 17 y 18 abordan cuestiones complementarias al proceso de traducción, pero no por ello menos importantes, puesto que inciden ostensiblemente en cualquiera de sus fases. El motivo de explicitarlas después de las pautas 1 a 14 se debe precisamente al objetivo pedagógico de no entorpecer la interacción de los macro y microprocesos establecidos en el comentario de una manera consecutiva, aunque dinámica. En el ejemplo de Döblin, ya hemos visto que la fase de documentación (15) es condición necesaria para entender y valorar el texto en todas sus dimensiones, sobre todo en un entorno didáctico. Mediante el estudio de estos factores, el docente puede evaluar a través del comentario la competencia documental adquirida: conocimiento lexicográfico y terminológico, actitud y conocimiento sobre textos paralelos, dominio de Internet, conocimiento cognitivo, conocimiento de las normas textuales de la tipología del TM, el estilo, etc. Los estudiantes deben acostumbrarse a indicar las fuentes consultadas para que el docente disponga de un marco documental de cada alumno que le ayude a entender los aciertos y errores cometidos. En línea con una de las corrientes de investigación más prolíficas de los 
últimos años (Wolf y Fukari, 2007, entre otros), la pauta 16 trata el papel social del traductor e implica, por ejemplo, cualquier revisión en torno a las instrucciones del encargo y el posible diálogo con los otros actantes del proceso. Reproducir en el aula el contexto de una traducción real puede parecer difícil, pero tal vez no lo sea tanto en aquellas traducciones que se realizan en grupo, donde cada estudiante puede desempeñar un papel social determinado cuya representación fundamenten en el comentario: editor, traductor, corrector de estilo, corrector ortotipográfico, etc. La pauta 17 permite comunicar al docente problemas relacionados con el tiempo de realización de la traducción. Algunos estudiantes no consiguen acabar su traducción en el tiempo establecido en los exámenes porque pueden estancarse por diversas razones en un momento dado (tropiezos lingüísticos, problemas de documentación, dificultades de producción del TM, problemas de revisión, etc.). Si consideramos que la variable tiempo desempeña un papel esencial en el proceso traslativo, el docente puede comprobar el motivo de estos problemas. Por último, la pauta 18 se basa principalmente en evaluar el conocimiento declarativo del estudiante en interacción con el conocimiento procedimental. Aquí se incluiría la evaluación de los conocimientos teóricos interdisciplinares aplicados a la práctica traslativa.

\section{CONCLUSIÓN}

El punto de partida de esta contribución ha sido la carencia latente de andamiajes teóricos y metodológicos en didáctica de la traducción literaria que alcancen a describir la complejidad de esta materia y ayuden al estudiante a traducir de forma profesional. Para combatir esta necesidad, proponemos un retorno a la introspección como herramienta para la reflexión argumentada sobre estrategias de traducción. Dicha introspección implica abordar el proceso de aprendizaje de forma cualitativa, a través de una metodología interdisciplinar que parta del conocimiento declarativo del estudiante y se complemente con el conocimiento procedimental. Para ello proponemos unos andamiajes epistémicos en torno a tres premisas: el contexto histórico-social; la imaginación, corporeización y cognición; y 
la enacción. A fin de tender un puente indispensable entre la teoría y la práctica, hemos ilustrado la metodología propuesta con un ejemplo extraído de la práctica profesional aplicado al trabajo en el aula. A falta de estudios de mayor calado que lo corroboren desde un punto de vista experimental y que serán objeto de posteriores investigaciones, esperamos haber demostrado que desde una perspectiva cognitiva y con las correspondientes pautas elaboradas y secuenciadas por el profesor (a través por ejemplo del comentario traslativo) es posible que el estudiante reflexione no sólo sobre lo que hace, sino también sobre por qué lo hace. Como complemento a los sistemas constructivistas, creemos que el conocimiento de nuestra mente y su funcionamiento (metacognición) es determinante para avanzar en el proceso de aprendizaje, en especial en un terreno tan resbaladizo como es el de la traducción literaria, en el que la norma se caracteriza por su constante quebrantamiento. Defendemos que el buen traductor es aquel capaz de reflexionar de manera responsable sobre su tarea, dejando margen a la intuición allí donde sea necesario. Dicha reflexión debe estar a la altura de la complejidad de su objeto. Creemos que los últimos avances en lingüística cognitiva pueden contribuir a aproximarse a un parámetro tan importante en traducción literaria y $\tan$ difícil de abordar desde la didáctica como es la creatividad.

\section{BIBLIOGRAFÍA}

BeLL, Roger, Translation and Translating: Theory and Practice, London \& New York, Longman, 1991.

BURÓN OREJAS, Javier, La autoobservación (selfinonitoring) como mecanismo de autoconocimiento y de adaptación, Tesis doctoral, Universidad de Deusto, 1988.

BURÓN OREJAS, Javier, Enseñar a aprender: Introducción a la metacognición, Bilbao, Ediciones Mensajero, 2006.

DE BEAUGRANDE, Robert; DRESSLER, Wolfgang, Introduction to Text Linguistics, London \& New York, Longman, 1981.

DöвLIN, Alexander, Wadzeks Kampf mit der Dampfturbine, München, Deutscher Taschenbuch Verlag, 1918/1987. 
FAUCONNIER, Gile; TURNer, Mark; The Way We Think. Conceptual Blending and the Mind's Hidden Complexities, New York, Basic Books, 2002.

García Álvarez, Ana M., "Evaluating Student's Translation Process in Specialised Translation", en The Journal of Specialised Translation (Jostrans) 7, 2007, 139-163.

García Álvarez, Ana M., "Evaluando la metacognición sobre la traducción en el aula. Diserio de una cuestionario de preguntas abiertas", en Revista electrónica de Didáctica de la Traducción e Interpretación (Redit) 6 [Monográfico: Didáctica de la traducción desde una perspectiva cognitiva], 2011,1-19.

GONG, Seonja, Alfred Döblins Berliner Roman, "Wadzeks Kampf mit der Dampfturbine", Dogilmunhak. Koreanische Zeitschrift für Germanistik, 44 (2003), H. 4, 2003, 300-316. Disponible en <http:// kgg.german.or.kr/kr/kzg/kzgtxt/88-16.pdf> Consultado el 20-I2013.

GRICE, H. Paul, "Further Notes on Logic and Conversation", en COLE, P. (ed.), Syntax and Semantics IX: Pragmatics, New York, Academic Press, 1978, págs. 113-127.

HATIM, Basil; MASON, Ian, Discourse and the Translator, London \& New York, Longman, 1990.

HATIM, Basil; MASON, Ian, The Translator as Communicator, London \& New York, Routledge, 1997.

HÖNIG, Hans G, Konstruktives Übersetzen, Tübingen, Stauffenburg, 1997.

KAUTZ, Ulrich, Handbuch Didaktik des Übersetzens und Dolmetschens, München, Iudicium, 2000.

KusSMAUL, Paul, Training the Translator, Amsterdam \& Philadelphia, John Benjamins Publishing, 1995.

KUSSMAUL, Paul, Kreatives Übersetzen, Tübingen, Stauffenburg, 2000.

LAKOFF, George, Women, Fire and Dangerous Things. What Categories Reveal about the Mind, Chicago, University of Chicago Press, 1987.

LANGACKER, Ronald W, Foundations of Cognitive Grammar, Vol. I, Theoretical Prerequisites, Standford, Standford University Press, 1987.

Martín de BueY, Francisco; MARTín Palacio, María Eugenia et al., "Procesos metacognitivos: estrategias y técnicas", Profes.net, 2007, en $<$ http:/ / www.profes.net/rep_documentos/Monograf/1PEI_ProcMetacog nitivos_b.pdf>. Consultado el 29-XI-2011.

NORD, Christiane, Textanalyse und Übersetzen. Theoretische Grundlagen, Methoden und didaktische Anwendung einer übersetzungsrelevanten Textanalyse, Heidelberg, Julius Groos Verlag, 1988.

NORD, Christiane, Translating as a Purposeful Activity. Functionalist Approaches Explained, Manchester, St. Jerome Publishing, 1997.

ORMROD, Jeanni E, Aprendizaje humano, Madrid, Pearson, 2005. 
RILE', Anthony W, Nachwort zu Wadzeks Kampf mit der Dampflurbine, Mulnchen, Deutscher Taschenbuch Verlag, 1987.

RISKU, Hanna, Translatorische Kompetenz. Kognitioe Grundlagen des Uiberselzens als Expertentätigkeit, Tübingen, Stauffenburg, 1998.

Rosch, Eleanor, "Principles of Categorization", en ROSCH, E.; LlOYD, B.B. (eds.), Cognition and Categorization, Hillsdale, N.J., Lawrence Erlbaum Associates, 1978, págs. $27-48$.

RUtZ DE MENDOZA, Francisco J, Metonymy, grammar and communication, Granada, Comares, 2002

Sáfenz, Miguel, (ed.); DÖbun, Alfred, Berlín Alexanderplatz, Madrid, Cátedra, 2002

SANTANA LÓPEZ, Belén; DöBLIN, Alfred, Wadzek contra la turbina de vapor, Madrid, Impedimenta, 2011.

Sevtllano GarCía, María Luisa, Didáctica en el siglo XXI. Ejes en el aprendizaje y enseñanza de calidad. Madrid, McGraw Hill, 2005.

SNELL-HORNBY, Mary, Translation Studies. An Integrated Approach, Amsterdam/Philadelphia, John Benjamins Publishing, 1988.

TODA Castán, Claudia, "Ideas y expectatioas del estudiante de traducción respecto a la traducción literaria", en TESI, Teoría de la Educación. Educación y Cultura en la Sociedad de la Información 13(1), 2012, págs. 266-316. Disponible enhttp://campus.usales/ revistas_trabajo/index.php/revistatesi/article /view/8796/9002 [Consultado el 18-I-2013].

TOURY, Guideon, Descriptioe Translation Studies and Beyond, Amsterdam/Philadelphia, John Benjamins Publishing, 1995.

VEGA ENCABO, Jesús, "Mentes hibridas: cognición, representaciones externas y artefactos epistémicos", en AIBR. Revista de Antropología Iberoamericana. Ed. Electrónica, Madrid, Antropólogos Iberoamericanos en Red, 2005.

VERMEER, Hans; WITTE, Heidrun, Mögen Sie Zistrosen? Scenes $\mathcal{E}$ frames $\mathcal{E}$ channels im translatorischen Handeln, Heidelberg, Julius Groos, 1990.

WIISON, Robert A, Boundaries of the Mind. The Individual in the Fragile Sciences: Cognition, New York, Cambridge University Press, 2004.

WOLF, Michaela; FUKARI, Alexandra (eds.), Constructing a Sociology of Translation, Amsterdam, John Benjamins, 2007. 